\title{
ЗНАЧЕНИЕ ЛИШЕНИЯ ПРАВА ЗАНИМАТЬ ОПРЕДЕЛЕННЫЕ ДОЛЖНОСТИ ИЛИ ЗАНИМАТЬСЯ ОПРЕДЕЛЕННОЙ ДЕЯТЕЛЬНОСТЬЮ В СИСТЕМЕ УГОЛОВНЫХ НАКАЗАНИЙ
}

\section{THE MEANING OF DEPRIVATION OF THE RIGHT TO HOLD CERTAIN POSITIONS OR ENGAGE IN CERTAIN ACTIVITIES IN THE SYSTEM OF CRIMINAL PENALTIES}

\section{A. Filimonov}

Summary: The article discusses the features of the place and purpose of punishment in the form of deprivation of the right to hold certain positions or engage in certain activities in the crime prevention system, and also provides a brief overview on the application of this type of criminal punishment.

Keywords: punishment, law enforcement agencies, official, crime, convict.

\author{
Филимонов Андрей Анатольевич \\ преподаватель, Владивостокский филиал ФГКОУ ВО \\ «ДВЮИ МВД России» \\ andrei_84-05@mail.ru
}

Аннотация: В статье рассмотрены особенности места и предназначения наказания в виде лишения права занимать определенные должности или заниматься определенной деятельностью в системе профилактики преступлений, а также представлен краткий обзор по применению данного вида уголовного наказания.

Ключевые слова: наказание, правоохранительные органы, должностное лицо, преступление, осужденный. $\mathrm{y}$ головно-правовая политика России в последнее время носит достаточно противоречивый характер, что находит выражение в наличии двух законодательных тенденций: с одной стороны происходит криминализация новых деяний, с другой стороны - общая тенденция, направленная на ослабление уголовного карательного воздействия. Данные процессы связаны с быстрым изменением социальной обстановки, что в свою очередь приводит к изменению, возникновению, либо исчезновению определенных угроз для общественной безопасности. Корректировка данной деятельности предполагает проведение соответствующих криминологических исследований, в том числе, связанных с анализом действенности уголовных наказаний в отношении определенных групп преступлений.

Внесение большого количества изменений в УК, УПК и УИК РФ говорит о существенной нестабильности, как процесса законотворчества, так и уголовной политики. Безусловно такая ситуация усложняет работу правоохранительной и судебной системы России. Отметим, что в целом судебная система демонстрирует понимание поставленных перед ней задач и направлена на обеспечение, прежде всего, правового статуса личности и интересов всего общества в борьбе с криминальными проявлениями.

В деятельности судебной системы России данные тенденции привели к существенным корректировкам правоприменительных задач, связанных с правильным и сбалансированным режимом деятельности в рамках Федерального закона от 07.03.2011 г. № 26-Ф3 [1] и Ф3 от 07.12.2011 г. № 420-Ф3 [2]. Основной задачей принятия данных нормативных актов мы видим улучшение государственной правовой защиты граждан при осуществлении судебной власти, дальнейшее совершенствование процесса борьбы с криминальными проявлениями, а также совершенствование системы правосудия с учетом общей тенденции по либерализации.

Гуманизация уголовного законодательства и правоприменительной практики заключается в изменениях, касающихся применения соответствующих видов уголовных наказаний и иных мер в отношении осуждаемых с наилучшим соответствием степени общественной опасности, характеру совершенного деяния, личности виновного и достижения целей исправления в отношении конкретного лица. Применительно к наказанию в виде лишения права занимать определенные должности или заниматься определенной деятельностью данные тенденции выражаются в увеличении числа лиц, к которым применяется такое наказание. Соответственно количество осужденных к данному виду наказания, состоящих на учете у уголовно-исполнительных инспекциях ФСИН России составляло: в 2004 г. - 10435 человек; в 2005 г. - 11619; в 2006 г. - 12793; в 2007 г. - 14500; в 2008 г. - 16134, в том числе в качестве основного - 3940; в 2009 г. - 18220, в том числе в качестве основного - 4291; 
в 2010 г. - 20481, в том числе в качестве основного 6176; в 2011 г. - 22260; в 2012 г. - 21799; в 2013 г. - 21578; 2014 г. - 19416; в 2015 г. - 31122; в 2016 г. - 96939; в 2017 г. - 140179; в 2018 г. - 145703; в 2019 - 138574 [3].

Специфическим содержательным признаком изучаемого наказания является его должностная принадлежность, которая в свою очередь обуславливает его предназначение и особое место в системе наказаний.

Рассматривая статистические характеристики совершаемых должностных преступлений, можно констатировать, что принимаемые государством меры по борьбе с ними не приносят значительных результатов.

Следственным комитетом РФ в 2017 году - расследовано 4760 преступлений (включая преступления прошлых лет) о даче и получению взяток и всего окончено уголовных дел о коррупционных преступлениях - 10797, в 2018 году в период с января по сентябрь) - расследовано 3986 преступлений (включая преступления прошлых лет) о даче и получению взяток и всего окончено уголовных дел о коррупционных преступлениях - 8409 [4].

Преступления против государственной власти, интересов государственной службы и службы в органах местного самоуправления включают в себя состав злоупотребление должностными полномочиями.

Проведенный статистический анализ показывает, что за последние годы регистрация фактов злоупотреблений возросла в 1,5 раза.

Указанные преступления, как правило, влекут назначение наказания, также и, в виде лишения права лишение права занимать определенные должности или заниматься определенной деятельностью.

Мнения ученых не однозначны и разделяются в отношении рассматриваемого наказания: большинство склоняются к мнению, что его карательное воздействие отличает и отграничивает его от иных мер уголовно-правового характера, другие склоняются к позиции, что все без исключения меры уголовно-правового характера обладают карательными признаками и оказывают ограничительное воздействие на правовой статус лица.

Уголовно-правовое воздействие предполагает наличие карательной составляющей, как соответствующей справедливой осуждающей реакции на деяние [5]. Coответственно карательная составляющая определяет содержание уголовно-правового воздействия и все его последствия. В.К. Дуюнов к их числу относит: предупредительное воздействие уголовно-правовых норм; возможности освобождения лица от уголовной ответственности по нереабилитирующим основаниям; применение в отношении виновного лица необходимого наказания или иных мер уголовно-правового характера; закрепление за осужденным лицом специального правового статуса - судимости в течение срока наказания, а также после его отбытия [5].

Содержательная сторона уголовно-правового воздействия включает в себя количественные и качественные показатели, определяющиеся видом соответствующего наказания и сроком на которое оно назначается, либо применением иных мер уголовно-правового воздействия.

На основании данных положений можно определить основные критерии, позволяющие разграничить уголовно-правовые средства воздействия и меры уголовно-правового характера.

Данные критерии позволяют по ключевым признакам охарактеризовать внутреннее содержание мер уголовно-правового воздействия.

К первому критерию мы относим основания для применения определенной меры уголовно-правового воздействия, а именно совершение виновным лицом определенного запрещенного общественно опасного деяния, ответственность за которое содержится в нормах уголовного закона. Второй критерий указывает на определенный своеобразный характер таких мер, связанный с очерченным набором правоограничений.

Характер рассматриваемого вида уголовного наказания включает в себя определенный объем карательного воздействия, который характерен только для данного наказания.

Качественное содержание данного наказания выражается в свойственных ему правоограничениях.

С количественной стороны наказание характеризуются величиной законодательно определенных правоограничений.

Следовательно, с содержательной стороны рассматриваемое наказание выражается в карательном воздействии, как уголовного наказания, а сущность заключается в лишении определенных прав.

По мнению некоторых ученых, на основании определений закрепленных в ст. 43 УК РФ, сущностью уголовного наказания не является карательная составляющая.

В.Д. Филимонов считает, что кара как определение наказания не используется в уголовном законодательстве именно по этой причине, хотя они синонимы с точки зрения буквального значения данных слов [6]. По 
мнению других авторов, наоборот высказывается позиция о том, что кара - это всегда уголовное наказание, а негативные последствия, выражающиеся в определенных негативных последствиях для осужденного и направлены на осознание данным лицом своей вины. «Без кары наказание потеряло бы всякое предупредительное значение» [7].

По мнению С.И. Дементьева карательная составляющая наказания состоит из установленных законом негативных последствий, которые претерпевает лицо в ходе отбывания уголовного наказания [8].

Данная позиция является довольно спорной, поскольку вступает в противоречие с основными положениями уголовного законодательства, например, с принципом гуманизма в ст. 7 УК РФ, что в последующем может создать ситуацию по применению необоснованно жестких уголовно-правовых мер в отношении осужденных под прикрытием исправления осужденных и предупреждения новых преступлений, а так же приведет ухудшению правового положения личности [9].

Мы же полагаем, что наказание в виде лишения права занимать определенные должности или заниматься определенной деятельностью в своей содержательной части не преследует каких-либо дополнительных целей, связанных с оказанием карательного воздействия на виновного, а его специфической особенностью (предназначением) является именно недопущение или профилактирование совершения преступлений определенным лицом в будущем, что не связано с суровостью наказания или объемом карательного воздействия оказываемого иными наказаниями на виновного.

В настоящее время система уголовных наказаний сложилась из следующих тринадцати видов: штрафа; лишения права занимать определенные должности или заниматься определенной деятельностью; лишения специального, воинского или почетного звания, классного чина и государственных наград; обязательных работ; исправительных работ; ограничения по военной службе; ограничения свободы; принудительных работ; ареста; содержания в дисциплинарной воинской части; лишения свободы на определенный срок; пожизненного лишения свободы и смертной казни.

Все наказания разделены законодателем на основные, дополнительные и смешанные.

Основные виды наказаний не предусматривают правового механизма по их присоединению в качестве дополнительных наказаний.

Дополнительные наказания могут быть присоединены только в качестве дополнения к основному виду, усиливая карательное воздействие в отношении лица. Такие наказания, помогают в достижении всех целей наказания, дополняя правоограничения, с учетом всех обстоятельств совершенного деяния и иных факторов.

К таким наказаниям относится: лишение специального, воинского или почетного звания, классного чина и государственных наград. Указанный вид наказания допустимо применять только в качестве вспомогательного наказания к остальным.

Применение трех видов уголовных наказаний предполагает их назначение, как в качестве основных, так и дополнительных. К ним законодателем были отнесены штраф, лишение права занимать определенные должности или заниматься определенной деятельностью и ограничение свободы.

Наказания в виде лишения права занимать определенные должности или заниматься определенной деятельностью - довольно распространенное наказание в статьях УК РФ, оно включено в состав порядка $18 \%$ санкций всех статей Особенной части в виде дополнительного наказания, и только около 4 \% в качестве основного вида наказания [10]. В настоящее время, в действующей редакции УК РФ 43\% всех статей включают рассматриваемый вид наказания в качестве дополнительного и 6,5 \% в качестве основного наказания соответственно.

Так, проведенный анализ Особенной части УК РФ показал:

В разделе 7 «Преступления против личности» в главе 16 «Преступления против жизни и здоровья» рассматриваемый вид наказания предусмотрен в 10-ти статьях из 25, общим количеством - 19 санкций и только в качестве дополнительного вида наказания; в главе 17 «Преступления против свободы, чести и достоинства личности» - в 3-х санкциях 3-х статей из 6, и также только в качестве дополнительного наказания; в главе 18 «Преступления против половой свободы, чести и достоинства личности», рассматриваемое наказание представлено в 18-ти санкциях во всех 5-ти статьях и только в качестве дополнительного наказания; в главе 19 «Преступления против конституционных прав и свобод человека и гражданина» мы видим данное наказание в 21 санкции в 12 статьях из 20, из них в 7 статьях законодателем предусмотрено 9 санкций с данным наказанием в качестве основного вида (ст. 137 «Нарушение неприкосновенности частной жизни», ст. 138 «Нарушение тайны переписки, телефонных переговоров, почтовых, телеграфных или иных сообщений», ст. 139 «Нарушение неприкосновенности жилища», ст. 140 «Отказ в предоставлении гражданину информации», ст. 141.1. «Нарушение порядка финансирования избирательной кампании кандидата, избирательного объединения, деятельности инициатив- 
ной группы по проведению референдума, иной группы участников референдума», ст. 142 «Фальсификация избирательных документов, документов референдума, документов общероссийского голосования», ст. 145.1. «Невыплата заработной платы, пенсий, стипендий, пособий и иных выплат»); в главе 20 «Преступления против семьи и несовершеннолетних», рассматриваемое наказание предусмотрено в 7 санкциях 6-ти статей из 9-ти и только в качестве дополнительного наказания.

В разделе 8 «Преступления в сфере экономики», в главе 21 «Преступления против собственности ни в одной из 17 статей законодателем не было предусмотрено такое наказание; в главе 22 «Преступления в сфере экономической деятельности», рассматриваемое наказание присутствует в 58 санкциях 28 статей из 58, при этом в качестве основного предусмотрено в 5-ти санкциях 4-х статей (ст. 169 «Воспрепятствование законной предпринимательской или иной деятельности», ст. 170 «Регистрация незаконных сделок с недвижимым имуществом», ст. 170.2 «Внесение заведомо ложных сведений в межевой план, технический план, акт обследования, проект межевания земельного участка или земельных участков либо карту-план территории», ст. 189 «Незаконные экспорт из Российской Федерации или передача сырья, материалов, оборудования, технологий, научно-технической информации, незаконное выполнение работ (оказание услуг), которые могут быть использованы при создании оружия массового поражения, вооружения и военной техники»); в главе 23 «Преступления против интересов службы в коммерческих и иных организациях» данное наказание присутствует в 16-ти санкциях в 6-ти статьях из 7 и только в качестве дополнительного.

В разделе 9 «Преступления против общественной безопасности и общественного порядка», в главе 24 «Преступления против общественной безопасности», данное наказание присутствует в 23-х санкциях 10-ти статей из 42-х и только в качестве дополнительного наказания; в главе 25 «Преступления против здоровья населения и общественной нравственности», такое наказание предусмотрено в 29 санкциях 17-ти статей из 35, из них в 3-х санкциях 3-х статей в качестве основного (ст. 236 «Нарушение санитарно-эпидемиологических правил», ст. 243.2 «Незаконные поиск и (или) изъятие археологических предметов из мест залегания», ст. 243.3 «Уклонение исполнителя земляных, строительных, мелиоративных, хозяйственных или иных работ либо археологических полевых работ, осуществляемых на основании разрешения (открытого листа), от обязательной передачи государству обнаруженных при проведении таких работ предметов, имеющих особую культурную ценность, или культурных ценностей в крупном размере»; в главе 26 «Экологические преступления» - в 21 санкции 14 статей из 18, при этом в качестве основного вида наказания в 8-ми санкциях 8-ми статей (ст. 250 «За- грязнение вод», ст. 251 «Загрязнение атмосферы», ст. 252 «Загрязнение морской среды», ст. 253 «Нарушение законодательства Российской Федерации о континентальном шельфе и об исключительной экономической зоне Российской Федерации», ст. 254 «Порча земли», ст. 255 «Нарушение правил охраны и использования недр», ст. 257 «Нарушение правил охраны водных биологических ресурсов», ст. 262 «Нарушение режима особо охраняемых природных территорий и природных объектов»; в главе 27 «Преступления против безопасности движения и эксплуатации транспорта» такое наказание закреплено в 15-ти санкциях 8-ми статей из 11, только в качестве дополнительного наказания; в главе 28 «Преступления в сфере компьютерной информации» рассматриваемое наказание предусмотрено в 4-х санкциях 3-х статей их 4-х, только в качестве дополнительного наказания.

В разделе 10 «Преступления против государственной власти», в главе 29 «Преступления против основ конституционного строя и безопасности государства», данное наказание присутствует в 20-тим санкциях 9-ти статей из 16-ти в качестве дополнительного наказания; в главе 30 «Преступления против государственной власти, интересов государственной службы и службы в органах местного самоуправления» предусмотрена 41 санкция с исследуемым наказанием в 15-ти статьях из 17, из них 7 санкций в качестве основного наказания в 6-ти статьях (ст. 285 «Злоупотребление должностными полномочиями», ст. 285.3 «Внесение в единые государственные реестры заведомо недостоверных сведений», ст. 286 «Превышение должностных полномочий», ст. 287 «Отказ в предоставлении информации Федеральному Собранию Российской Федерации или Счетной палате Российской Федерации», ст. 289 «Незаконное участие в предпринимательской деятельности», ст. 292.1 «Незаконная выдача паспорта гражданина Российской Федерации, а равно внесение заведомо ложных сведений в документы, повлекшее незаконное приобретение гражданства Российской Федерации»; в главе 31 «Преступления против правосудия» данное наказание закреплено в 7-ми санкциях 5-ти статей из 24-х, из них 2 санкции в 2-х статьях в качестве основного наказания (ст. 303 «Фальсификация доказательств и результатов оперативно-разыскной деятельности», ст. 315 «Неисполнение приговора суда, решения суда или иного судебного акта»; в главе 32 «Преступления против порядка управления» предусмотрено только 2 санкции в 2-х статьях из 22-х и только в качестве дополнительного наказания.

В раздел 11 главе 33 «Преступления против военной службы», данный вид наказания закреплен в 5-ти санкциях 3-х статей из 21, в качестве дополнительного наказания.

В разделе 12 главе 34 «Преступления против мира и безопасности человечества» рассматриваемое нака- 
зание предусмотрено в 2-х санкциях 2-х статей из 21 в качестве дополнительного наказания.

Таким образом, исследуемый вид наказания присутствует во всех разделах УК РФ, за исключением главы 21 «Преступления против собственности». Всего из 367 действующих статей УК РФ, рассматриваемый вид наказания, предусмотрен в 158 статьях, что близко к 50 \% от общего количества составов преступлений. В качестве основного наказания предусмотрено в 24 статьях УК РФ.

Набольшее распространение, данное наказание в качестве основного вида закономерно получило в главах 19, 26 и 30 УК РФ за преступления против конституционных прав свобод человека и гражданина, за экологические преступления и преступления против государственной власти, интересов государственной службы и службы в органах местного самоуправления. Несколько реже законодатель предусмотрел его в главах 21, 22, 23, 28 и 31 УК РФ за преступления против собственности, преступления в сфере экономической деятельности, против интересов службы в коммерческих и иных организациях, преступления в сфере компьютерной информации и против правосудия.

Лишение прав как дополнительный вид наказания наиболее распространен за преступления: в сфере экономической деятельности; против общественной безопасности; против жизни и здоровья, против правосудия, против здоровья населения и общественной нравственности; основ конституционного строя и безопасности государства; против государственной власти, интересов государственной службы и службы в органах местного самоуправления - главы 22, 24, 25, 29, и 30 соответственно УК РФ. Такая ситуация вполне объяснима стремлением законодателя оказать профилактическое воздействие на определенное лицо с помощью применения в отношении него дополнительных правовых ограничений, связанных, прежде всего, с его особым профессиональным статусом использованным для совершения деяния.

Выявленная тенденция к расширению количества составов, предусматривающих применения рассматриваемого наказания (в качестве дополнительного прирост составляет более $50 \%$ за 10 лет), а также общая распространённость изучаемого наказания в санкциях статей УК РФ, связанный с профессиональной сферой деятельности говорит о возрастающем значении данного наказания в борьбе с данной категорий преступлений, что в свою очередь говорит, об особом месте в системе уголовных наказаний рассматриваемого наказания. Особое значение, оно приобретает в отношении противоправной деятельности в иных сферах, связанных с наличием специальной подготовки и осуществлением деятельности в определенных областях, таких как, управление различными видами транспорта и механизмами, профессиональная или любительская охота или рыболовство, деятельность в сфере частных охранных структур, экологическая сфера, в связи, с его особым предназначением, состоящим в недопущении или профилактике совершения преступлений определенным лицом, связанным с его должностным статусом или определенной профессиональной сферой деятельности в будущем.

\section{ЛИТЕРАТУРА}

1. Федеральный закон от 07.03.2011 № 26-Ф3 «0 внесении изменений в Уголовный кодекс Российской Федерации» // Собрание законодательства РФ, 14.03.2011, № 11, ст. 1495.

2. Федеральный закон от 07.12.2011 № 420-Ф3 «0 внесении изменений в Уголовный кодекс Российской Федерации и отдельные законодательные акты Российской Федерации» // Собрание законодательства РФ, 12.12.2011, № 50, ст. 7362.

3. Отчеты о работе уголовно-исполнительных инспекций по форме УИИ-1 и ФСИН-1 [Электронный ресурс] // URL: http://www.fsin.su/structure/inspector/iao/ statistika/Xar-ka\%20v\%20YII/ (дата обращения: 12 апреля 2021 г.).

4. Сведения о деятельности Следственного Комитета Российской федерации за 2013-2018 гг. [Электронный ресурc] // URL: http://sledcom.ru/activities/ statistic (дата обращения: 12 апреля 2021 г.).

5. Дуюнов В.К. Механизм уголовно-правового воздействия: теоретические основы и практика реализации: дис.... д-ра юрид. наук. Тольятти, 2001. С. 27.

6. Филимонов В.Д. Принципы уголовного права. - 2-е изд. - М.: ЦентрЮрИн-фоР, 2012. - 376 с.

7. Наумов А.В. Российское уголовное право. Курс лекций: В 2 т. М., 2004. Т. 1: Общая часть. С. 494. Беляев Н.А. Уголовная политика и пути ее реализации. Л., 1986. С. 64.

8. Дементьев С.И. Лишение свободы. Уголовно-правовые и исправительные аспекты. Ростов н/Д, 1981. С. 45.

9. П Полубинская С.В. Цели уголовного наказания. М., 2010. С. 7 - 8.

10. Ничуговская 0.Н. Лишение права занимать определенные должности или заниматься определенной деятельностью в системе наказаний, предусмотренных уголовным кодексом российской федерации, и целесообразность его применения в отдельных случаях // Право. 2009. № 2. С. 89.

() Филимонов Андрей Анатольевич (andrei_84-05@mail.ru). 